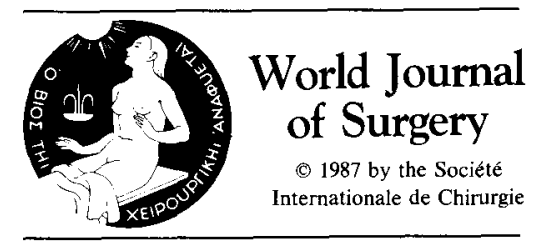

\title{
The Use of Ultrasound During Spinal Cord Surgery
}

\author{
Jonathan M. Rubin, M.D., Ph.D., and William F. Chandler, M.D. \\ Departments of Radiology and Surgery, University of Michigan Medical School, Ann Arbor, Michigan, USA
}

\begin{abstract}
Intraoperative spinal ultrasonography is now considered an indispensable tool in many operations on the spine and spinal cord. Using ultrasonography, surgeons can now easily find and evaluate lesions within the spinal cord, dural sac, and along the ventral margin of the vertebral column during operations. Syrinxes, intra- and extramedullary tumors, hematomas, bone fragments, bullet fragements, cysts, and discs can be easily located and treated under ultrasonic guidance. In this article, we described the techniques used in peforming this procedure, normal anatomy, and images of various types of pathologic lesions.
\end{abstract}

The accurate preoperative and intraoperative localization of lesions of the spine and spinal cord is vitally important for neurosurgeons. Because of the extreme delicacy of the spinal cord, the surgeon must be precisely aware of the position of the operative field, and where he/she is headed at all times.

Preoperative localization of spinal cord lesions has attained a high technological level with such tests as myelography, computed tomography (CT), and magnetic resonance imaging (MRI). MRI has recently become the diagnostic imaging technique of choice for imaging the spinal cord and spinal subarachnoid space [1-3]. It directly images the spinal cord with high contrast and detail, and it does not require the injection of contrast material, like CT and myelography, to achieve this visualization. Furthermore, unlike MRI, CT and myelographic examinations have been generally disappointing in the detail of the spinal cord they can display even with contrast material in the subarachnoid space [4-8].

Unfortunately, despite its exquisite detail of the spinal cord, MRI is worthless as an intraoperative tool. Once in the operating room, the neurosurgeon must use his/her best judgment in determining the location and extent of lesions based on the MRI displayed abnormalities. Furthermore, it is obvious that any manipulations performed during an operation will not be displayed on preoperative diagnostic scans. It is at this point that real-time ultrasonography has its greatest utility.

It turns out that real-time ultrasonography is almost the perfect intraoperative instrument. Once the bone has been surgically removed, ultrasonography is an excellent localizing

Reprint requests: Jonathan M. Rubin, M.D., Ph.D., Department of Radiology, Box 0030, University Hospital, BID502/0030, 1500 E. Medical Center Drive, Ann Arbor, Michigan 48109-0030, U.S.A. device, since merely by pointing the scanhead at a lesion, all of the 3-dimensional coordinates defining the position of a lesion relative to the scanhead are defined $[9,10]$. Since the neurosurgeon holds the scanhead, the position of a lesion is defined relative to the position of his/her hands, precisely the relationship a surgeon employs to define the location of lesions during an operation. The result is equivalent to literally pointing at an abnormality, exactly what one would want. Since the technique is performed in real-time and is safe, ultrasonography can be used repeatedly to evaluate the status of an operation. Not only can neurosurgeons localize spinal abnormalities, but they can

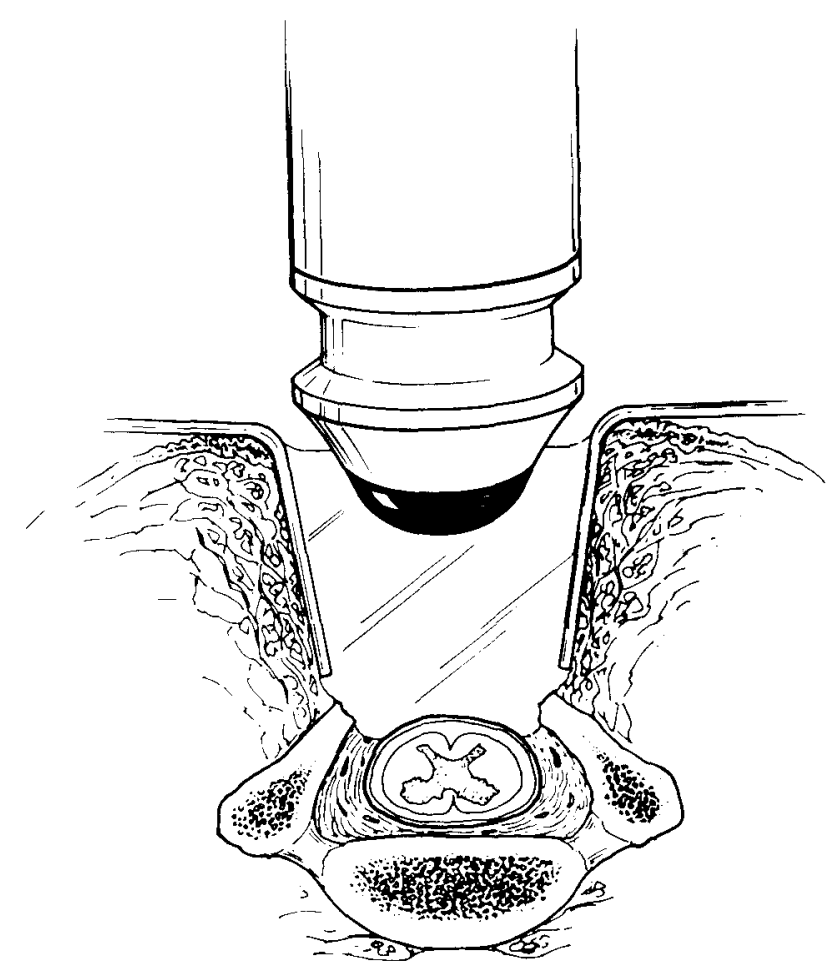

Fig. 1. Diagram showing a laminectomy with a scanhead inserted. The saline produces a fluid path so that the spinal cord can be scanned without touching it. Reprinted with permission of publisher [9]. 

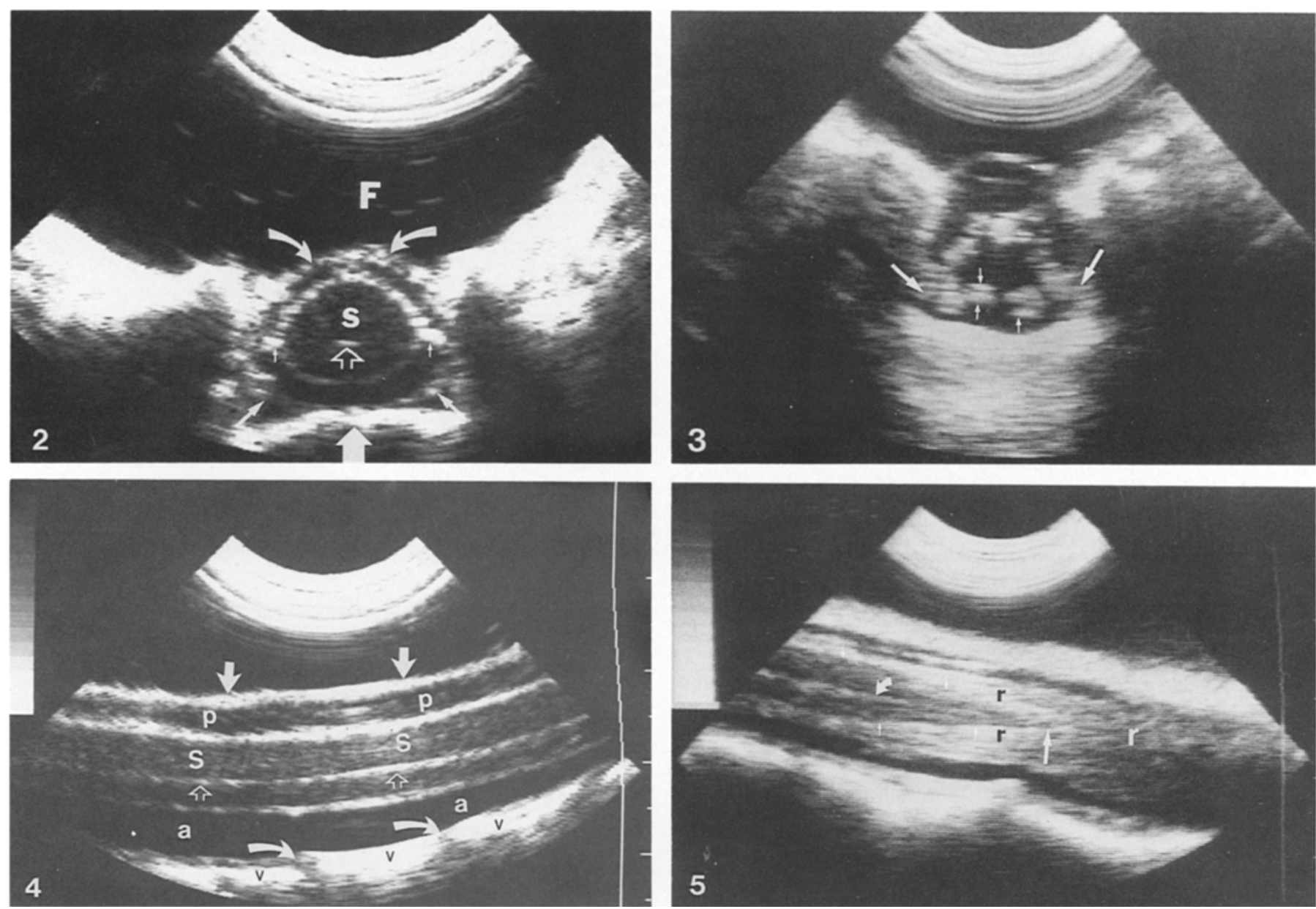

Fig. 2. Normal transverse scan of a spinal cord. A fluid path $(\mathrm{F})$ is present in the near field separating the scanhead from the posterior dura mater (curved arrows). (Posterior will always be positioned at the top of the images.) The posterior subarachnoid space is the clear space between the posterior dura mater and the spinal cord (s). The dentate ligaments (small arrows) are the small lines on each side of the spinal cord. The central canal (hollow arrow) is represented by a localized reflection in the ventral half of the spinal cord. In this scan, the anterior dura mater (middle-sized arrows) is resolved at about 5 o'clock and 8 o'clock. The dura mater cannot, however, be resolved along the posterior surface of the vertebral body (large arrow). The anterior subarachnoid space appears as an anechoic area between the spinal cord and vertebral body. Reprinted with permission of publisher [24].

Fig. 3. Normal cauda equina. Transverse scan through the cauda equina demonstrating individual nerve roots ( $s m a l l$ arrows) in cross-section. Two large groups of nerve roots (large arrows) are visible near the neural foramina. Reprinted with permission of publisher [24].

Fig. 4. Normal longitudinal scan of spinal cord. The posterior dura mater (solid arrows) is the first reflection beneath the scanhead. (On longitudinal scans, cephalad will always be on the left side of the image.) The spinal cord (s) appears as a long ribbon beneath the anechoic posterior subarachnoid space (p). The central canal (hollow arrows) is a line running through the ventral half of the spinal cord. The posterior surfaces of the vertebral bodies ( $v$ ) are discontinuous reflections separated by disc spaces (curved arrows). The anterior subarachnoid space (a) lies between this line of discontinuous reflections and the spinal cord. Reprinted with permission of publisher [24].

Fig. 5. Normal conus medullaris. Longitudinal scan showing the conus medullaris narrowing into the filum terminale. The boundary of the spinal cord (small arrows) and the site of origin of the filum (large arrow) are visible. Multiple nerve roots (r) can be seen surrounding the conus and extending into the cauda equina. The central canal is again demonstrated on this scan (curved arrow).

also confirm immediately during an operation that a maneuver has actually produced the intended effect $[9,10]$.

\section{Technique}

All of the operations to be described were performed with the patients in the prone position. With a prone patient, the laminectomy can be filled with sterile saline providing a fluid path several centimeters deep through which scanning can be performed (Fig. 1). The fluid path has several functions: it keeps the near-field cap artifact of the scanhead from falling within the image of the spinal cord, it increases the amount of the spinal cord that can be imaged within a sector, and it allows scanning of the intraspinal contents without having to touch the intrathecal structures themselves $[9,10]$. Finally, the scanhead can be positioned so that its area of best focus falls within the spinal cord.

The technique can be performed from an anterior approach through a corpectomy as well [11]. The procedure is identical. The space provided by the resected vertebral body is filled with saline producing a fluid path. The only difference is that now the more ventral anatomic structures are nearest to the scanhead. 
Because the spinal cord is a thin object, high-frequency transducers should be used for scanning. We have routinely used a $7.5-\mathrm{MHz}$, short-focus, mechanical-sector scanner (Advanced Technology Laboratories, Bothel, Washington, U.S.A.), but we have also used a $10-\mathrm{MHz}$, linear-array scanner with success. In general, any high-frequency transducer that can fit into the laminectomy should work as well.

\section{Normal Anatomy}

On transverse scans (Fig. 2), the posterior dura mater is imaged first as a curved line convex toward the scanhead. The dura mater extends to the bony margins of the laminectomy. Under the dura mater, the posterior subarachnoid space is seen as a fluid-filled space. The spinal cord, imaged immediately under the posterior subarachnoid space, appears as an oval mass in cross-section. The precise shape of the spinal cord varies depending on the portion of the cord being imaged. The central canal is visible as a dot within the ventral half of the spinal cord $[9,10,12]$, and serves as a useful landmark. When there are masses present displacing the spinal cord, the cord can frequently be identified by the presence of the central canal echo. This echo can be followed down to the conus medullaris, where the spinal cord disappears into clumps of nerve roots (Fig. 3). Lateral to the spinal cord are the dentate ligaments (Fig. 2). They appear as lines extending from the margins of the cord. The anterior spinal artery and various marginal arteries are visible pulsating along the periphery of the spinal cord on the real-time images, although they are rarely visible on static scans.

Anterior to the spinal cord, the anterior subarachnoid space and the posterior surface of vertebral bodies and discs are visible. Although the sound does not go through bone and poorly penetrates disc material, the effects of anterior compression by bony or disc fragments are clearly demonstrable.

The anatomy is equally simple to evaluate on longitudinal scans (Fig. 4). The posterior dura mater appears as a line passing through the laminectomy. The posterior subarachnoid space is a clear area between the dura mater and the spinal cord. The spinal cord is seen extending through the subarachnoid space between the posterior dura mater and vertebral bodies-disc spaces. Again the central canal is visible, this time as a line, running through the ventral half of the cord. The diameter of the spinal cord depends on the portion of the spinal cord being imaged. It starts out broad in the cervical region, tapering down to a line, the filum terminale, in the lumbar area (Fig. 5).

The anterior subarachnoid space is again seen as a clear area in front of the spinal cord. Sometimas adhesions or piaarachnoid webs are seen within the subarachnoid spaces. The posterior surfaces of the vertebral bodies are bright reflections interspersed with discontinuities at the disc spaces (Fig. 4). Virtually no sound penetrates the bony vertebrae, but some sound may pass through discs. Clearly again, although generally only the posterior surfaces of discs and vertebrae are visible ultrasonically, the effects of compression of the spinal cord by these structures is easy to evaluate (see below).

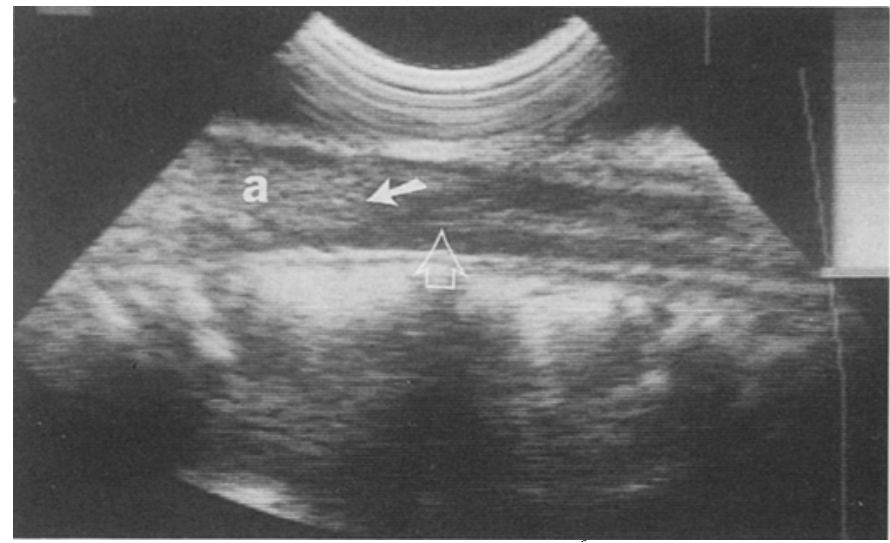

Fig. 6. Intramedullary astrocytoma. Longitudinal scan showing the inferior portion of a diffuse echogenic astrocytoma (a) of the spinal cord. Notice that the inferior margin of the tumor (arrow) can be defined relative to the comparatively anechoic normal neural tissue and the appearance of the central canal (hollow arrow). This is probably a gross boundary, however, since microscopic tumor infiltration cannot be imaged ultrasonically.

\section{Intramedullary Tumors}

\section{Tumors}

Intraoperative ultrasonography has proven very useful in the localization and resection of intramedullary spinal cord tumors $[9,13-15]$. With the great improvements in diagnostic imaging techniques for spinal cord tumors, i.e., MRI, the neurosurgeon usually has a good idea of the location and extent of an abnormality before the operation begins. Once, however, the laminectomy has been performed and the dura mater or spinal cord exposed, the ability of ultrasonography to characterize precisely these lesions is of significant value. These tumors have been universally more echogenic than the normal spinal cord [9, 13-15] (Fig. 6). They generally expand the cord while destroying the normal intramedullary anatomy, in particular the central canal echo [12].

Furthermore, intraoperative ultrasonography can, in many ways, display the intramedullary anatomy with more detail than even MRI. In particular, intramedullary cysts are demonstrated much better by ultrasonography than by any other technique $[9$, $11,15,16]$. It is a generally accepted fact that ultrasonography is the modality of choice for characterizing cysts in the body [17], and this has proven true in the spinal cord [9, 11, 15]. Sonography exquisitely details the internal architecture of cysts, showing multiple septae and solid nodules along the walls. The surgeon can select the most direct and safest access for drainage, thus minimizing trauma to the spinal cord.

Cysts associated with intramedullary tumors can occur cephalad to the mass producing symptoms and signs suggesting syringomyelia [18]. Besides draining the apparent syrinx (see below), the localization of the tumor is important. Ultrasonography can accomplish this (Fig. 7).

As all neurosurgeons know, the identification of cysts within a lesion may be of great importance to the progress of an operation. The drainage of cystic spaces in tumors can greatly decrease the mass effect of a lesion, and even if the entire mass 

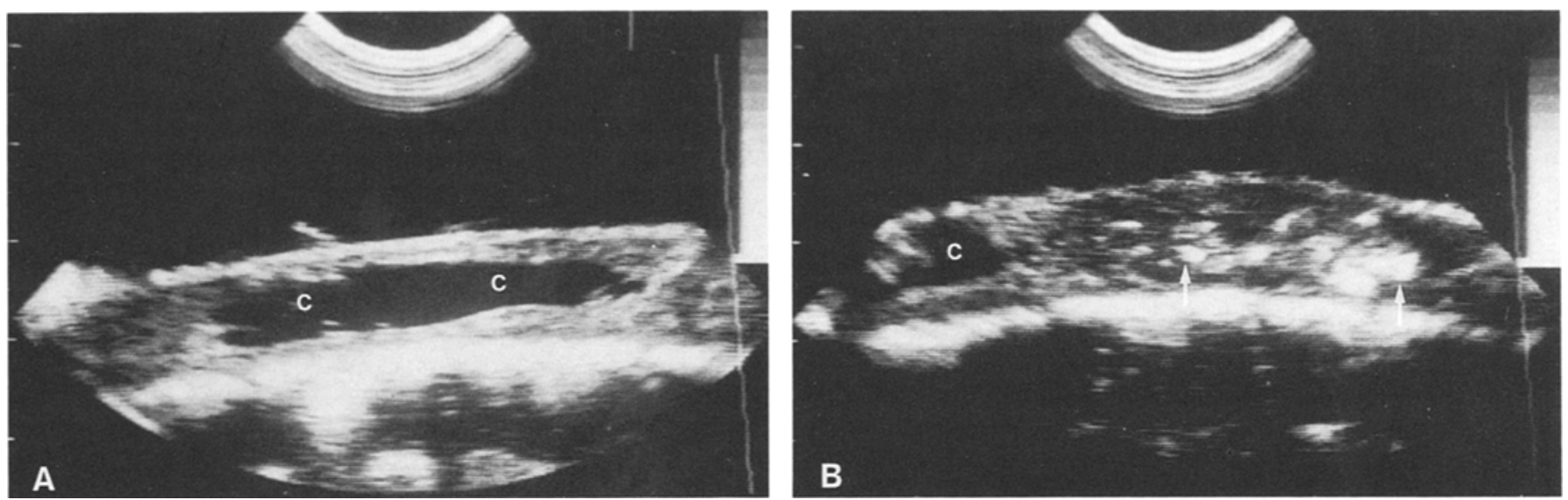

Fig. 7. Astrocytoma with central cyst, syrinx. A. Longitudinal scan of thoracic spinal cord with centrally located cyst (c). B. Inferior scan showing an echogenic intramedullary astrocytoma. Multiple calcifications are present, some of which have been labeled with arrows. Surprisingly, none of the calcifications shadowed. There is a portion of the cyst (c) seen cephalad to the tumor. Reprinted with permission of publisher [25].

cannot be removed, a patient's symptoms may be greatly alleviated solely due to a cyst drainage. Furthermore, by entering directly into a cyst, a neurosurgeon gains immediate access to the heart of a tumor, thus decreasing the difficulty of the dissection. Hence, the identification of cysts is definitely of more than academic interest. Yet, all of the present-day diagnostic tests are flawed in their ability to demonstrate cysts. There have been many documented examples of false-positive intramedullary cysts on delayed metrizamide CT scans [11]. In these cases, generally of myelomalacia of the spinal cord, metrizamide was thought to have been taken up within small channels in the neural tissue itself. Upon ultrasound scanning, no cysts are found. Thus, ultrasonography can prevent dangerous myelotomies and cyst explorations. In the case of MRI, ultrasonography is again showing an increased sensitivity and specificity for cysts. Recent publications have shown that the standard long $T_{1}$, long $T_{2}$ times used to diagnose cysts on MRI only hold when there is a significant water component present $[16,19]$. Up to one-third of cysts, particularly those with large amounts of protein, may not have these properties [19]. Hence, apriori it is very difficult to tell if a mass is in fact a cyst. Such examples in cystic tumors of the spinal cord have recently been described [16] (Fig. 8). Both cystic areas that looked solid and solid areas that appeared cystic were demonstrated. Lastly, ultrasonography can show multiple cysts in a lesion when CT, myelography, or MRI may not show any $[9,11,15,16]$.

\section{Syringomyelia}

Ultrasonography has significantly altered the treatment and perception of syringomyelia. It was generally believed that the cystic spaces within a syrinx were interconnected. Yet, ultrasonography has shown this not to be the case [9]. At the very least, there are frequently multiple septae dividing the main cavity. In extreme cases, there may be multiple, discrete spaces that do not interconnect. These spaces would have to be drained individually in order to decompress the syrinx (Fig. 9). Besides identifying the complex structure of these cavities before insertion of drains, ultrasonography can be used to confirm the effectiveness of the operative decompression once a drain has been inserted (Fig. 10).

\section{Extramedullary Masses}

Extramedullary tumors are generally easily seen by ultrasound. As with intramedullary tumors, they are more echogenic than the spinal cord (Fig. 11). In particular, meningiomas, schwannomas, and metastases have all met this criterion. The classic finding with cervical and thoracic extramedullary tumors is an echogenic mass displacing the spinal cord to the side on transverse scans and either anteriorly or posteriorly on sagittal scans (Fig. 11). Besides its easily identifiable geometry, the spinal cord can also be identified by the presence of the central canal echo in it. Although destroyed by intramedullary tumors, extramedullary masses usually spare this echo $[12,20]$. Unfortunately, in cases with extramedullary masses causing severe spinal cord trauma or contusion, the central canal echo can be obscured [12, 14, 20].

From the perspective of the neurosurgeon, ultrasonography can greatly facilitate operations on extramedullary tumors. Lesions located posteriorly are often easy to find, although sonography will still identify the point on the dura mater closest to the lesion. This can facilitate opening the dura mater. The resection of anterior masses is, however, much more complex [21]. Frequently, the neurosurgeon must retract the spinal cord in order to visualize these lesions. Spinal cord retraction is a dangerous maneuver, one which most neurosurgeons would rather avoid. With ultrasonography, anterior masses can easily be identified and mapped without manipulating the spinal cord. Lastly, the surgeon can use sonography to evaluate the operative field after resecting the mass to confirm the completeness of the operation.

In a similar fashion, it is simple to identify bulging discs or bony bars (Figs. 12, 13). The site of compression of the disc or bar is readily visible by ultrasound even though the disc or bar cannot be seen in its entirety. In many cases, it is possible to differentiate between the two using their sound transmitting properties. Sound is completely reflected from bone while only partially reflected by discs. Therefore, if there is through 


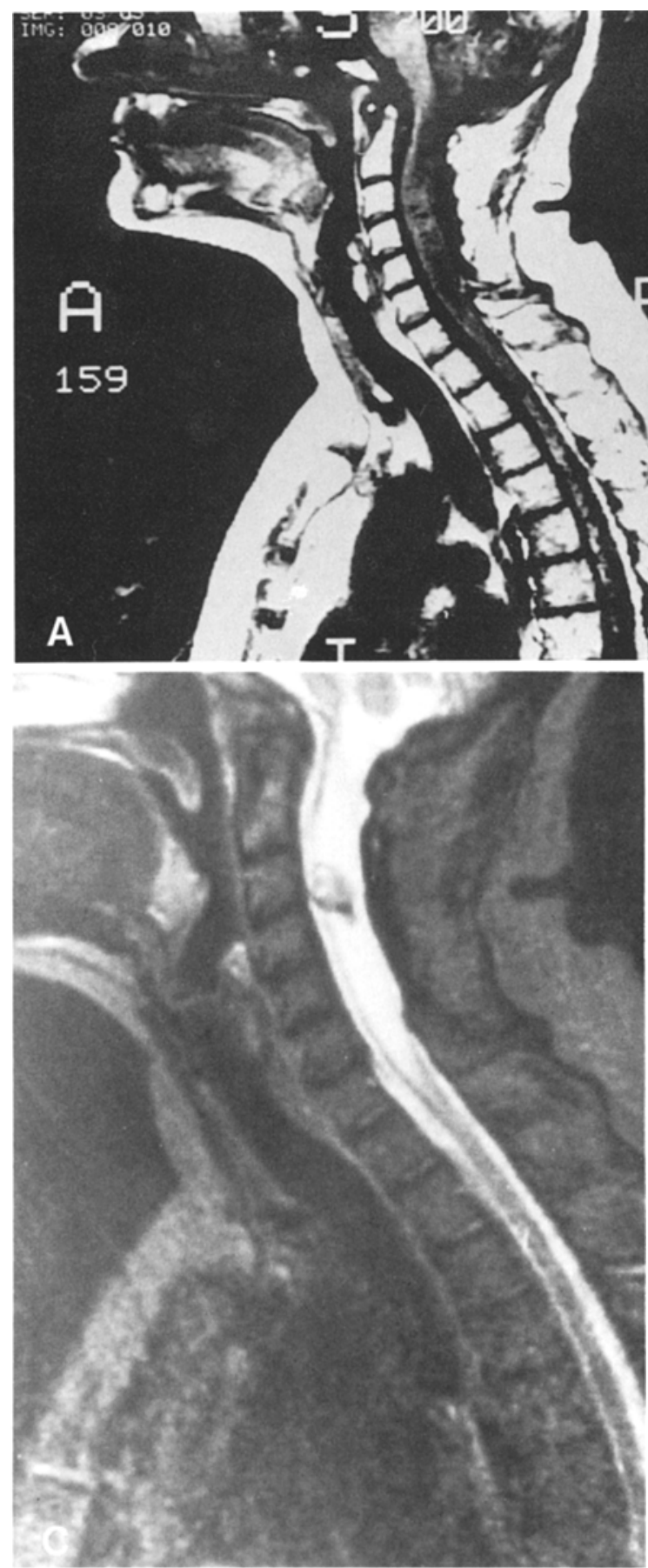

Fig. 8. Erroneous cyst on MRI-1.5 T MR scans and intraoperative ultrasound scans demonstrating an expansile lesion of the cervical spinal cord which was prospectively diagnosed as a large cystic collection with a solid, central nodule. A. $\mathrm{T}_{1}=$ weighted $(\mathrm{TR} 400 \mathrm{msec}$, TE $25 \mathrm{msec}$ ). B. $\mathrm{T}_{2}=$ weighted $(\mathrm{TR} 2,000 \mathrm{msec}$, TE 25 $\mathrm{msec}$ ). C. TR $2,000 \mathrm{msec}$, TE $50 \mathrm{msec}$. D. Longitudinal intraoperative ultrasound scan showing a diffusely infiltrating, mainly solid lesion of the cervical spinal cord with a localized, septated cystic area (arrows)

corresonding to the presumed "solid" nodule on MRI. E. Transverse scan again demonstrating localized cystic area (arrows) on the left-hand side of the spinal cord. Reprinted with permission of publisher [16].
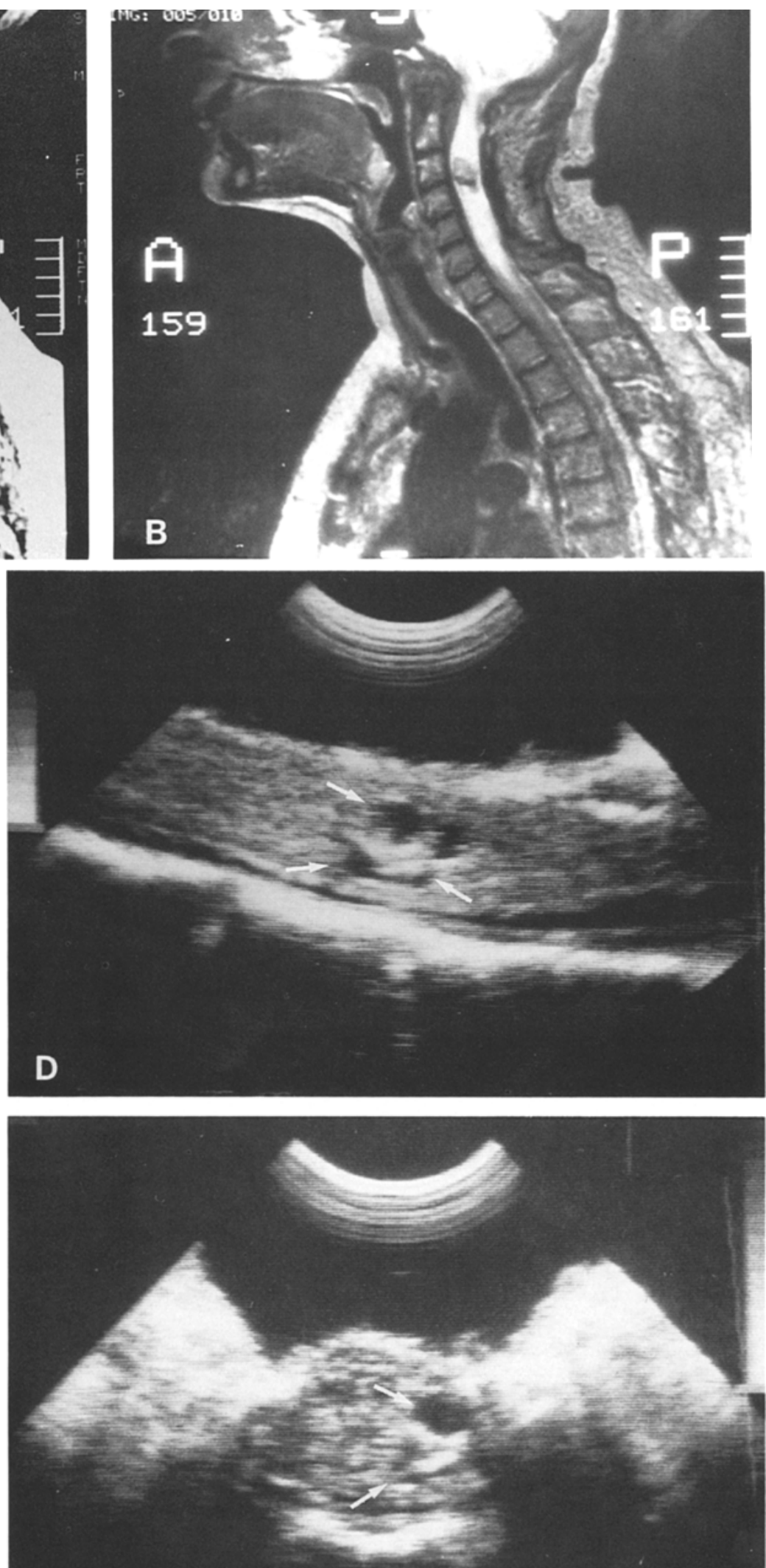

E 

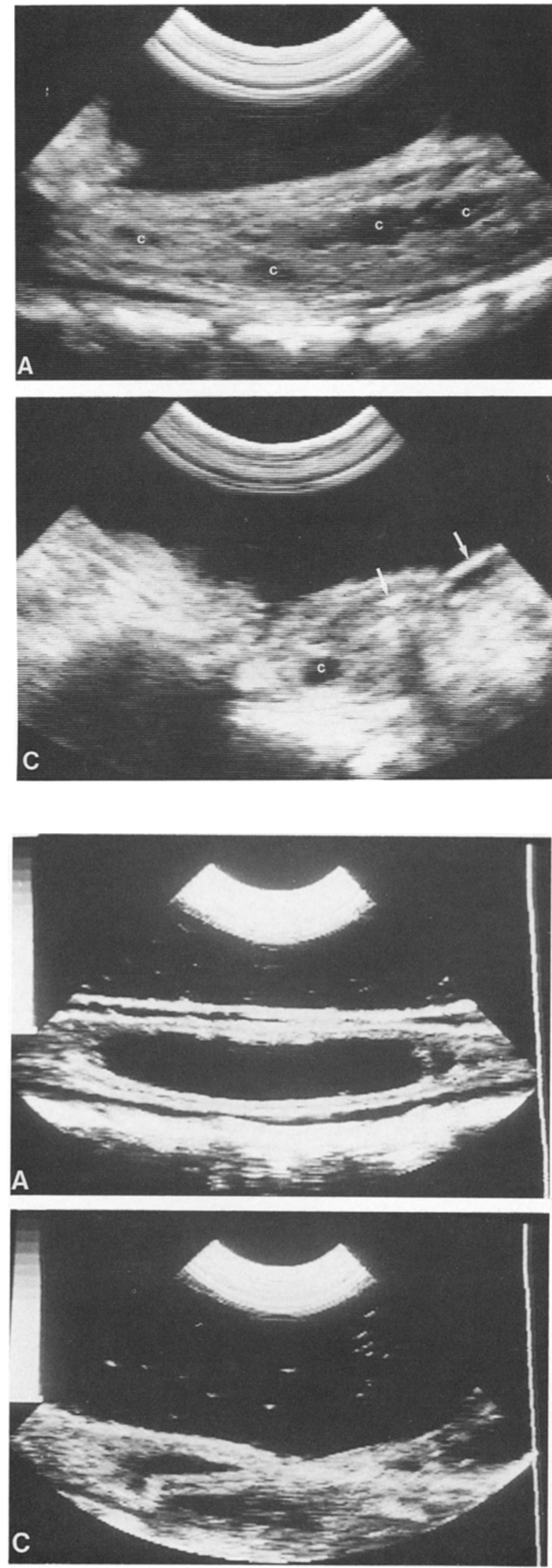

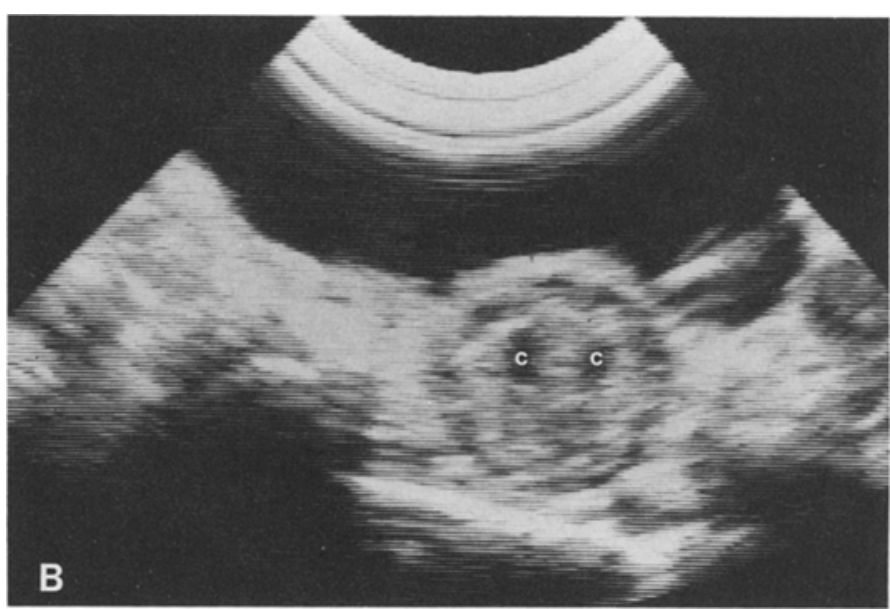

Fig. 9. Syringomyelia. A. Longitudinal ultrasonogram demonstrating multiple cystic spaces (c) in the spinal cord. B. Two dorsal cystic areas (c) are shown in this transverse slice. C. An oblique scan demonstrating a small catheter (arrows) in a collapsed dorsal cyst. Notice, however, that a ventral cyst (c) on the other side of the spinal cord has not collapsed. This patient showed improvement on one side but not the other. Reprinted with permission of publisher [9].

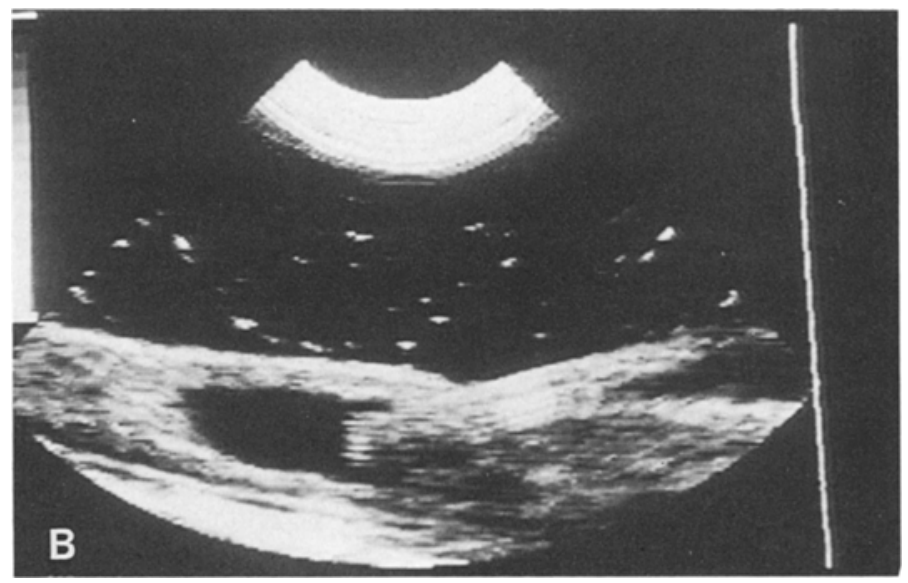

Fig. 10. Syringomyelia. A. Large syrinx on longitudinal scan. B. Shunt tube entering the syrinx posteriorly. C. Slightly later scan showing the shunt tube extending through the entire length of the cavity. Reprinted with permission of publisher [25]. 

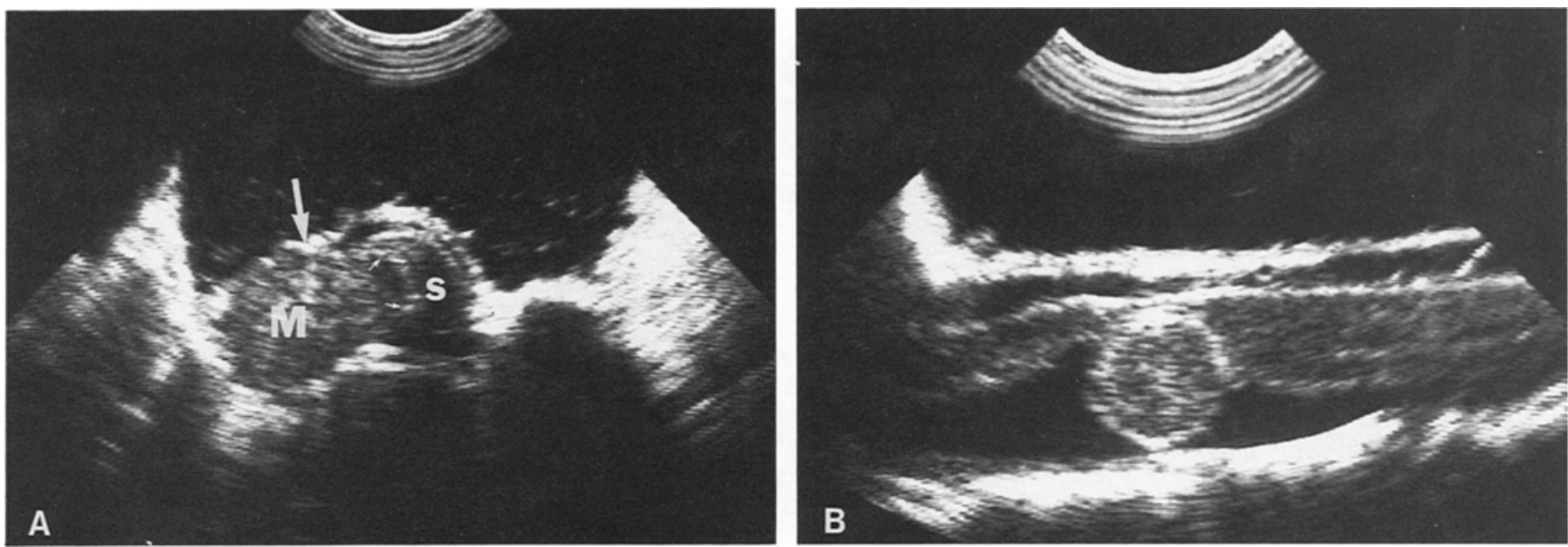

Fig. 11. Schwannoma. A. Transverse scan showing an intradural, extramedullary mass (M) displacing the spinal cord (s) laterally. The boundary between the cord and mass is well depicted (small arrows). Also, the dural reflection off the mass is identified (large arrow). B. Longitudinal sonogram showing the tumor displacing the spinal cord. Reprinted with permission of publisher [10].
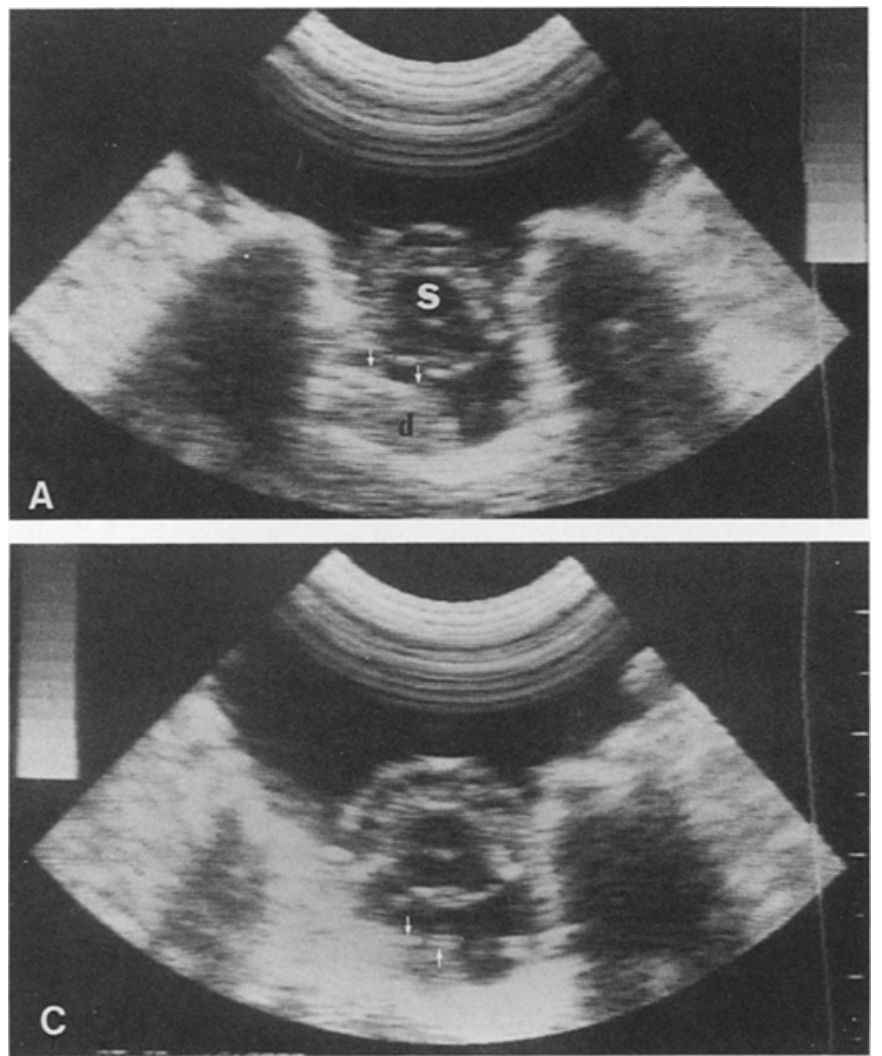

transmission, the surgeon is dealing with a disc (Fig. 12). Unfortunately, this maxim does not hold true universally. Some discs are so attenuating that very little if any sound can penetrate them, making it difficult to distinguish these discs from bars. Despite these shortcomings, the neurosurgeon can still use sonography to evaluate the operative results. Whatever

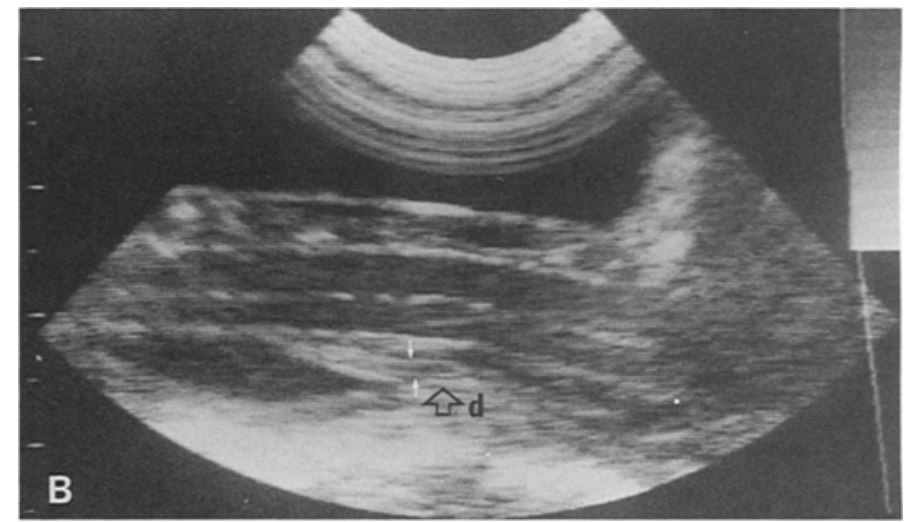

Fig. 12. Protruding disc. A. Thoracic disc fragment (d) displacing the spinal cord (s) posteriorly and laterally. Nerve roots (arrows) are draped over the disc as well. Notice that sound is able to penetrate the disc. B. Longitudinal scan of the disc (d) trapping a nerve root (arrows). The actual site of entrapment is marked (hollow arrow). C. Post-resection transverse scan showing removal of the compressing disc fragment. The nerve roots (arrows) are now no longer compressed, and the spinal cord has rotated back to its normal position. Reprinted with permission of publisher [24].

means is used to decompress the spinal cord or nerve roots, ultrasonography can detail the effects of the decompressive procedure. Ultrasonography can often document the need for further decompression of nerve roots or the spinal cord despite the fact that they are grossly decompressed by visual inspection [22].

In trauma cases, bone fragments are detectable as they alter 

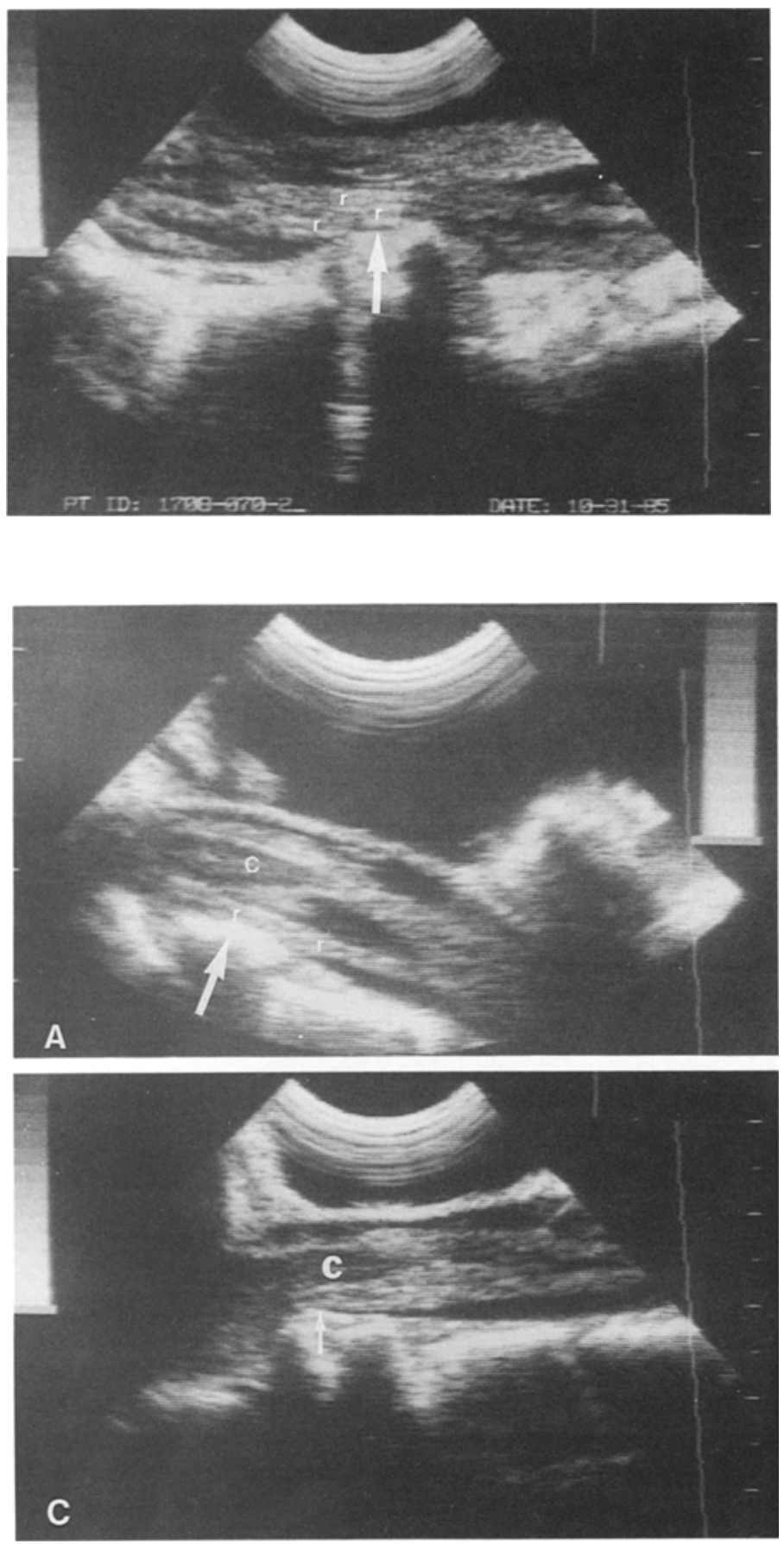

the path of either the spinal cord or nerve roots (Fig. 14). As with bony bars, the highly reflective fragment causes posterior acoustic shadowing, a very characteristic appearance. Shadowing makes localization of individual fragments quite easy. A recent article by Quencer et al. [22] has documented the usefulness of ultrasonography in these cases. In $45 \%$ of the cases in which ultrasonography was used to confirm the straightening of gibbuses in thoracic or lumbar fractures with Harrington rods or impaction of fragments, the initial decompression was inadequate, meaning there was continued compression of the spinal cord or nerve roots. An additional
Fig. 13. Bony bar. Longitudinal scan showing the site of entrapment (arrow) of several nerve roots (r) of the cauda equina by a bony bar. As compared to disc fragments (see above), no sound passes through the bone.

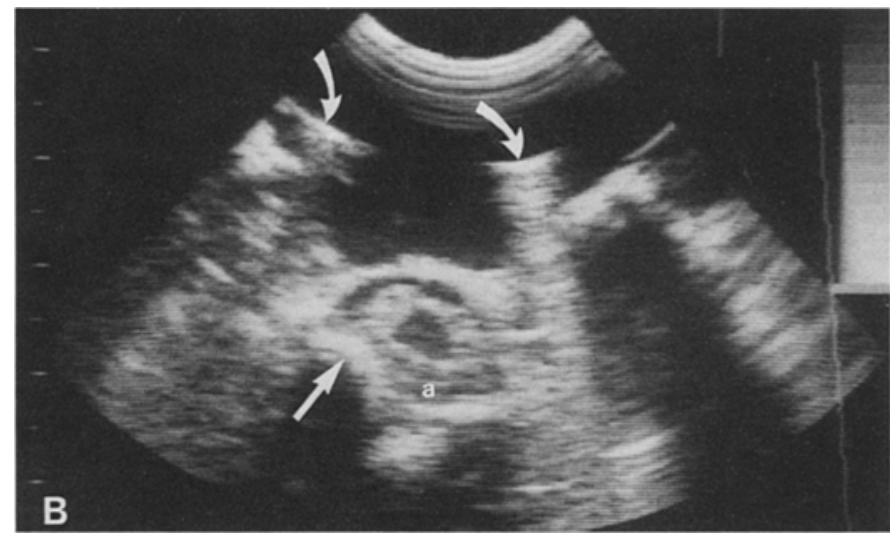

Fig. 14. Bony compression due to trauma. A. Longitudinal scan showing posterior displacement of the conus medullaris (c) and a directly compressed nerve root ( $r$ ) by a collapsed vertebral body (arrow). Note the abrupt change in the smooth curvature produced by the posteriorly displaced bone. Even though the bone is not seen in its entirety, the effect on the neural elements is obvious.

B. Transverse scan performed after instillation of Harrington rods (curved arrows) shows that some of the compression has been relieved on the left side with the appearance of subarachnoid space (a) between the spinal cord and vertebral body. There was, however, continued compression on the right from a bone fragment (arrow). C. Longitudinal scan along the right side of the neural canal after rods had been placed showing a site of continued compression of nerve roots (arrow) anterior to the conus medullaris (c). This area corresponded to the site of compression shown in the transverse scan above.

corrective procedure was required to correct the neural impingement. Without ultrasonography, such a determination could not have been made in the operating room. It would have, therefore, required an additional postoperative diagnostic procedure and possibly reoperation.

Bullet fragments cause shadowing as well, but the apearance of the shadow is very different and quite characteristic [23]. Rather than totally scattering or absorbing the ultrasound energy impinging on it, the sound causes the metal to ring like a bell. This ringing sends multiple echoes back to the transducer. The ultrasound scanner positions each echo behind the 


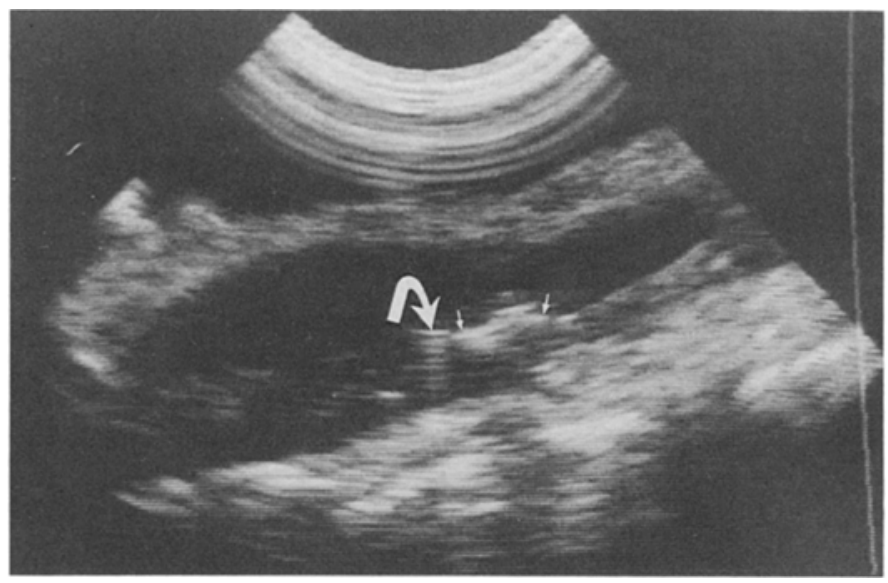

Fig. 15. Bone and bullet fragments. Scan through the cauda equina in a young male after a gunshot wound to the back. An echogenic bone fragment (arrows) was localized among the roots of the cauda. Cephalad to the bone fragment, a small bullet fragment (curved arrow) with a characteristic "comet-tail" artifact is seen. Reprinted with permission of publisher [26].

reflecting object producing a series of bright lines like a "comettail"' [23]. This appearance is almost diagnostic of metal and can be very useful in locating metallic fragments (Fig. 15).

\section{Résumé}

L'échographie opératoire rachidienne constitue une exploration indispensable au cours de nombreuses opérations effectuées sur le rachis et la moëlle. En employant l'échographie les chirurgiens peuvent facilement évaluer les lésions de la moëlle, du sac dural, de la partie antérieure de la colonne vertébrale au cours des interventions. Les fistules, les tumeurs extra et intra-médullaires, les hématomes, les fragments osseux, les fragments de projectile, les kystes, les disques peuvent être facilement découverts et traités sous la contrôle de l'échographie. Dans cet article sont décrites les techniques employées, l'anatomie normale et les images des diverses lésions.

\section{Resumen}

La ultrasonografía intraoperatoria espinal se considera hoy como un instrumento indispensable en numerosas operaciones sobre la columna vertebral y la medula espinal. Con el uso de ultrasonografía los cirujanos pueden fácilmente, en el curso de una operación, ubicar y evaluar lesiones dentro de la medula espinal y la dura y sobre el aspecto ventral de la columna vertebral. Siringos (fístulas), tumores intra- y extramedulares, hematomas, fragmentos óseos, fragmentos de bala, quistes, y discos pueden ser fácilmente localizados y tratados bajo guía de ultrasonido. En este artículo se describen las técnicas utilizadas en la realización del procedimiento, la anatomía normal, y las imágenes de diversos tipos de lesiones patológicas.

\section{References}

1. Young, I.R., Bailes, D.R., Burl, M., Collins, A.G., Smith, D.J., McDonnell, M.J., Orr, J.S., Banks, L.M., Bydder, G.M., Greenspan, R.H., Steiner, R.E.: Initial clinical evaluation of a whole body nuclear magnetic resonance (NMR) tomography. J. Comput. Assist. Tomogr. 6:1, 1982
2. Modic, M.J., Weinstein, M.A., Pavlicek, W., Starnes, D.L., Duchesneau, P.M., Boumphery, F., Hardy, R.J.: Nuclear magnetic resonance imaging of the spine. Radiology 148:757, 1983

3. Huk, W., Heindel, W., Deimling, M., Stetter, E.: Nuclear magnetic resonance (NMR) tomography of the central nervous system: Comparison of two imaging sequences. J. Comput. Assist. Tomogr. $7: 468,1983$

4. Hammerschlag, S.B., Wolpert, S.M., Carter, B.L.: Computed tomography of the spinal cord. Radiology 121:361, 1976

5. Gonsalves, C.G., Hudson, A.R., Horsey, W.J.: Computed tomography of the cervical spine and spinal cord. Comput. Tomogr. $2: 279,1978$

6. Lee, B.C.P., Kazam, E., Newman, A.D.: Computed tomography of the spine and spinal cord. Radiology 128:95, 1978

7. Haughton, V.M., Syvertsen, A., Williams, A.L.: Soft tissue anatomy within the spinal canal as seen on computed tomography. Radiology 134:649, 1980

8. Taylor, A.J., Haughton, V.M., Doust, B.D.: CT imaging of the thoracic spinal cord without intrathecal contrast medium. J. Comput. Assist. Tomogr. 4:223, 1980

9. Dohrmann, G.J., Rubin, J.M.: Intraoperative ultrasound imaging of the spinal cord. Syringomyelia, cysts, and tumors-a preliminary report. Surg. Neurol. 18:395, 1982

10. Rubin, J.M., Dohrmann, G.J.: Intraoperative ultrasonography of the spine. Radiology 146:173, 1983

11. Quencer, R.M., Morse, B.M.M., Green, B.A., Eismont, F.J., Brost, P.: Intraoperative spinal sonography: Adjunct to metrizamide CT in the assessment and surgical decompression of posttraumatic spinal cord cysts. Am. J. Roentgenol. 142:593, 1984

12. St. Amour, T.E., Rubin, J.M., Dohrmann, G.J.: Ultrasonic identification of the central canal of the spinal cord. Radiology 152:767, 1984

13. Braun, I.F., Raghavendra, B.W., Kricheff, I.I.: Spinal cord imaging using real-time high resolution ultrasound. Radiology 147:459, 1983

14. Hutchins, W.W., Vogelzang, R.L., Neiman, H.T., Fuld, I.T., Kowal, L.E.: Differentiation of tumor from syringohydromyelia: Intraoperative neurosonography of the spinal cord. Radiology $151: 171,1984$

15. Machi, J., Sigel, B., Jafar, J.J., Menoni, R., Beitler, J.C., Bernstein, R.A., Crowell, R.M., Ramos, J.R., Spigos, D.G.: Criteria for using imaging ultrasound during brain and spinal cord surgery. J. Ultrasound Med. 3:155, 1984

16. Rubin, J.M., Aisen, A.M., DiPietro, M.A.: Ambiguities in MR imaging of tumoral cysts in the spinal cord. J. Comput. Assist. Tomogr. 10:395, 1986

17. Rosenfield, A.T., Taylor, K.J.W., Jaffe, C.C.: Clinical applications of ultrasound tissue characterization. Radiol. Clin. North Am. $18: 31,1980$

18. Poser, C.M.: The relationship between syringomyelia and neoplasm. In American Lecture Series no. 262, American Lectures in Neurology, Springfield, Illinois, C.C. Thomas, 1956

19. Kjos, B.O., Brant-Zawadzki, M., Kucharczyk, W.: Cystic intracranial lesions: Magnetic resonance imaging. Radiology $155: 363,1985$

20. Knake, J.E., Gabrielsen, T.O., Chandler, W.F., Latack, J.T., Gebarski, S.S., Yang, P.F.: Real-time sonography during spinal surgery. Radiology $151: 461,1984$

21. Connolly, E.S.: Spinal cord tumors in adults. In Neurological Surgery, J.R. Youmans, editor, Philadelphia, W.B. Saunders, 1982, pp. 3211-3212

22. Quencer, R.M., Montalvo, B.M., Eismont, F.J., Green, B.A.: Intraoperative spinal sonography in thoracic and lumbar fractures: Evaluation of Harrington rod instrumentation. A.J.R. 145:343, 1985

23. Wendell, B.A., Athey, P.A.: Ultrasonic appearance of metallic foreign bodies in parenchymal organs. J.C.U. 9;133, 1981

24. Rubin, J.M., Dohrmann, G.J.: Intraoperative sonography of the spine and spinal cord. Sem. Ultrasound 6:48, 1985

25. Rubin, J.M., Dohrmann, G.J.: Intraoperative spinal ultrasonography. J.B.R.-B.T.R. $69: 9,1986$

26. Rubin, J.M., Dohrmann, G.J.: The spine and spinal cord during neurosurgical operations: Real-time ultrasonography. Radiology 155:197, 1985 